\title{
Análise do discurso e o uso dos meios de comunicação na política externa de boa vizinhança
}

\section{Discourse analysis and the use of media in the good neighbor policy}

\author{
Isaias Albertin Moraes ${ }^{1}$
}

\section{Resumo}

O presente artigo, fazendo uso da Análise do Discurso, buscou lançar um olhar na utilização e nos impactos causados pelos meios de comunicação, no Brasil, na Política Externa de Boa Vizinhança do governo de Franklin Delano Roosevelt, presidente dos Estados Unidos da América - EUA de 1933 a 1945. A realização de uma pesquisa que identifique a importância e as aplicações dos instrumentos midiáticos e culturais na Política Externa de Boa Vizinhança justifica-se e encontra sua relevância para melhor aproveitamento e amplo conhecimento dos variados instrumentos das Relações Internacionais. Os meios comunicacionais e a cultura, não raramente, são menosprezados na formulação da política externa dos Estados, porém, quando utilizados estrategicamente, são capazes de agirem sobre o coletivo e as nações, forjando as linhas de influência em dada conjuntura. Primeiramente, o estudo procurou traçar um panorama sobre os preceitos essenciais da Análise do Discurso, valendo-se, mormente, dos estudos de Michel Foucault. Posteriormente, foi realizado um breve levantamento bibliográfico e histórico, de fontes primárias e secundárias, com vistas a apresentar a produção discursiva da Política Externa de Boa Vizinhança e suas principais diretrizes para a América Latina, sobretudo, para o Brasil. O artigo procurou, ademais, sintetizar, na terceira parte do texto, as premissas fundamentais do uso dos meios de comunicação, essencialmente, a publicidade, o rádio e o cinema, para além de seu caráter informativo e de sua função de entretenimento. De posse desse conjunto de elementos, a pesquisa intentou verificar, no período em questão, a relevância dos mecanismos comunicacionais para construção de valores, entendimentos, ideais e identidades. $\mathrm{O}$ trabalho inferiu, por fim, que os aspectos culturais produzidos pela Política Externa de Boa Vizinhança e vendidos aos demais países latino-americanos divulgaram estilos de vida, conceitos, visões e foi uma das primeiras exportações de versões idealizadas do American way of Life.

Palavras-chave: Análise do discurso. Política externa de boa vizinhança. Diplomacia cultural. Meios de comunicação.

\begin{abstract}
This article, making use of discourse analysis, sough to cast an eye the use and impacts caused by the media in Brazil Foreign Policy Good Neighbor government of Franklin Delano Roosevelt, President of the United States of America - USA from 1933 to 1945. Carring out a survey to identify the importance and applications of media and cultural instruments in Foreign Policy Good Neighbor, justified and finds its relevance to better use and extensive knowledge of various instruments of International Relations. The media communication and culture, not infrequently, are overlooked in the formulation of foreign policy of states, however, when used strategically, are able to act on the collective and nations, forging lines of influence in a given situation. First, the study sought to give an overview on the key of discourse
\end{abstract}

\footnotetext{
${ }^{1}$ Pesquisador do Grupo de Análise de Prevenção de Conflitos Internacionais - GAPCon. Mestrando em Ciência Política e Relações Internacionais pelo Instituto Universitário de Pesquisas do Rio de Janeiro - IUPERJ. Especialista em Relações Internacionais pela Universidade de Brasília - UnB. Email: isaias.moraes@unisul.br
} 
analysis, using, primarily the studies of Michel Foucault. Later, there was a brief bibliography and history of primary and secondary sources, with a view to presenting the discursive production of the Foreign Policy Good Neighboor and its main guidelines for Latin America, especially to Brazil. The article sought, moreover, synthesize, in the third part of the text, the fundamental premises of the use of the media, essentially, advertising, radio and cinema in addition to its informative character and its entertainment function. Armed with this set of elements, the research brought verify the period in question, the relevance of the communication mechanisms for building values, understandings, ideals and identities. The study concluded, finally, that the cultural aspects, produced by the Foreign Policy Good Neighbor and sold to the other Latin American countries issued lifestyles, concepts, visions and it was one of the first exports of an idealized versions of American Way of Life.

Keywords: Discourse analysis. Foreign Policy Good Neighbor. Cultural Diplomacy; Media.

\section{Introdução}

Este artigo, tomando como perspectiva analítica os estudos de Michael Foucault sobre o discurso, buscou examinar qual foi a importância, as aplicações e os resultados do uso dos meios de comunicação, no Brasil, na Política Externa de Boa Vizinhança do governo de Franklin Delano Roosevelt, presidente dos Estados Unidos da América - EUA de 1933 a 1945.

O Brasil e toda a América Latina, durante o período estudado, tornou-se área de evidência na estratégia de defesa dos EUA, em razão da tensa conjuntura internacional que acabaria por eclodir com a Segunda Guerra Mundial. Nesse ensejo, foram desenvolvidos, pelos formuladores da política externa estadunidense, mecanismos e instituições para a batalha ideológica contra o modelo sociopolítico e econômico nazifascista que lograva terreno no imaginário dos latino-americanos.

Os EUA, para combater a rejeição ao American way of life, como a matriz de desenvolvimento a ser seguida pelos demais países americanos e para diminuir a influência nazifascista na região, começaram a utilizar de forma significativa e com eficiência os meios de comunicações, adotando, assim, uma política cultural expansionista.

Importante ressaltar que as relações entre poder e linguagem, amplamente abordadas por renomados autores, como Michel Foucault, Domenique Maingueneau, Norman Fairclough, Michel Pêcheux, Mikhail Bakhtin, entre outros, corroboram para o entendimento da análise do discurso cultural no período estudado.

O texto, desse modo, ao pensar os meios de comunicação como técnica discursiva, artefato de linguagem e produto histórico, optou por adotar, como suporte epistemológico para a proposta da pesquisa, a arqueologia social de Michel Foucault. Nessa, o discurso é tomado como uma prática social, historicamente determinada, que constitui os sujeitos e os objetos, sendo que, para assimilar o seu funcionamento, é necessário desconstruir os trajetos dos enunciados, as posições dos sujeitos em destaque, as materialidades que lançam realce aos sentidos e os conluios que os enunciados estabelecem com a história e a memória.

Tendo isso em mente, e partindo do princípio de que o discurso é heterogêneo e marcado pela história e pela ideologia - o trabalho empregará técnicas da pesquisa qualitativa, visando obter indicadores que permitam a inferência de conhecimentos relativos às condições de produção e de recepção dessas mensagens.

Além disso, como quase todas as pesquisas exploratórias, o estudo foi desenvolvido com o objetivo de proporcionar uma visão geral sobre determinada realidade. Enveredou-se, desse modo, pela linha da pesquisa bibliográfica e histórica, com uma abordagem sistemática, por meio de coleta, de organização e de avaliação crítica de dados de fontes primárias e secundárias, tais como: revistas, jornais, livros, fotografias, resoluções, portarias, discursos, entre outros. 


\section{Foucault e a Análise do Discurso (AD)}

O método arqueológico de Michel Foucault permite tematizar a relação entre verdades, saberes, valores, instituições e práticas sociais, de onde os discursos emergem. Para Foucault, o pesquisador social não deve investigar somente o que supostamente estaria subentendido nos documentos e nos textos, tampouco deveria procurar o que se gostaria de ter dito e não fora. A recomendação é, portanto, que o arquigenealogista descreva as condições de existência do discurso, do enunciado ou do conjunto de enunciados de determinada época ou cultura.

[...] a análise arqueológica como descrição dos discursos não deve se fechar no interior do próprio discurso. Pelo contrário, uma de suas ideias básicas é articular o acontecimento não discursivo, as formações discursivas com as formações não discursivas. Ela não permanece unicamente ao nível do discurso, embora esse seja o seu objeto, aquilo para o qual tudo converge, mas busca estabelecer uma relação com acontecimentos de outra ordem, seja ela técnica, econômica, social ou política (MACHADO, 1981, p. 166).

Ao elaborar conceitos primordiais para $\mathrm{AD}$, como: formação discursiva, função-enunciativa, sujeito-autor, biopoder, ordem do discurso, acontecimento, arquivo e heterogeneidade discursiva - Foucault construiu um vasto campo de questões das quais se pode estabelecer uma teoria do discurso, que seria resumida, de acordo com Gregolin (2007), nos seguintes pontos:

1.0 discurso é uma prática que provém da formação dos saberes e que se articula com outras práticas não discursivas.

2.Os dizeres e os fazeres inserem-se em formações discursivas, cujos elementos são regidos por determinadas regras de formação.

3.0 discurso é um jogo estratégico e polêmico, por meio do qual se constituem os saberes de um momento histórico.

4.O discurso é o espaço em que saber e poder se articulam (quem fala, fala de algum lugar, baseado em um direito reconhecido institucionalmente).

5.A produção do discurso é controlada, selecionada, organizada e redistribuída por procedimentos que visam a determinar aquilo que pode ser dito em certo momento histórico (GREGOLIN, 2007, p. 14-15).
A partir desses pressupostos, Foucault, ao apresentar uma arqueologia do saber, intenta esmiuçar as circunstâncias capazes de proporcionar o surgimento de certos enunciados e o impedimento de outros. Observa-se que nos períodos históricos, como o da Política Externa de Boa Vizinhança, há algumas ideias e valores que devem ser enunciadas, porém, há outras que precisam ser silenciadas.

Por meio dessa análise, Foucault estabelece, claramente, as relações entre os dizeres e os fazeres, ou seja, as práticas discursivas concretizam as atividades dos indivíduos na história. A discursividade tem, pois, uma densidade histórica, e desconstruir o discurso simboliza procurar entender a maneira como as verdades são fabricadas e difundidas. Assim, buscando as tramas entre a historicidade e a substancialidade dos discursos produzidos pela Política Externa de Boa Vizinhança, busca-se efeitos discursivos do dizer, que frutifica as noções, os conceitos e os temas de determinado momento histórico.

Salienta-se que, como os indivíduos são sociais e os significados são históricos, os discursos acabam por se defrontarem, esgrimam-se, comprometendose em disputas, que simbolizam os embates em torno dos mecanismos identitários. Foucault distinguiu, nessa dinâmica, uma microfísica do poder. Disseminados por todo o campo social, os micropoderes fomentam uma constante batalha pela busca da constituição de verdades, que são relativas, mutáveis e estão em ininterrupta reformulação, pois se moldam de acordo com o período histórico.

\footnotetext{
No fundo em qualquer sociedade, existem relações de poder múltiplas que atravessam, caracterizam e constituem o corpo social e que estas relações de poder não podem se dissociar, se estabelecer nem funcionar sem uma produção, uma acumulação, uma circulação e um funcionamento do discurso (FOUCAULT, 1979, p. 179).
}

Os micropoderes condensam e divulgam os propósitos de verdade de estratos da sociedade, em específico momento da história. As identidades são, portanto, construções discursivas. No período estudado, “o bom”, "o mau”, “o livre”, “o reprimido”, 
"o nazista", "o democrático", ou "o modelo de vida estadunidense", "o modelo nazifascista", "o pan-americanismo", "o pangermanismo" são relatividades instituídas pela incessante competição desses micropoderes.

Ressalta-se que, para Foucault, o poder está em todo lugar não por envolver tudo, mas por vir de todos os lugares, o poder é distribuído por complexas redes de relações sociais. (ROUSE, 1994, p. 109). Além disso, o autor descreve uma relação entre poder e saber, não havendo, desse modo, uma relação de poder sem constituição correlata de um campo de saber, nem saber que não suponha e não constitua ao mesmo tempo relações de poder (DELEUZE, 2006, p. 48).

Em Foucault é bem conhecido por sua insistência que o poder está "em todos os lugares, " isso, porém, não é afirmar que o poder está ao alcance de todos e em todas as esferas do tecido social de forma igual e indiscriminatória. Esta formulação desloca o poder como algo que emerge apenas em cenas explícitas de dominação ou regra que se dá. Em vez disso, o poder é compreendido na construção e organização dos indivíduos numa variedade de domínios e discursos, incluindo aqueles geralmente imaginados para ser livre poder, por exemplo, a ciência, o desejo sexual e as artes (BROWN, 2008, p. 67).

O poder, para o autor, compõe a realidade e a verdade, antes de oprimir ou ideologizar, dissimular ou alhear. $O$ poder não ignora a repressão, tampouco a ideologia, mas é um processo que provoca divergências constantes e embates que podem cambiar e revigorar ou, até mesmo, reverter a polaridade entre poder e resistência. Isto significa que o poder não é estabelecido de cima para baixo, mas é descrito como um mecanismo relacional formado em determinada contextura, parcialmente identificáveis por meio dos efeitos ideológicos presentes na vida dos indivíduos.

Foucault não concebe tais relacionamentos como sendo impostas de cima para baixo. A configuração das relações de poder emerge do apoio que as relações de força encontrar um no outro, formando assim uma cadeia ou um sistema, ou, pelo contrário, a disjunção e contradições que os isolam uns dos outros (ROUSE, 1994, p. 110).
Verifica-se que a análise de poder, no olhar de Foucault, é tida como atividade social, historicamente estabelecida e com variadas estruturas de seu exercício na sociedade. Assim, além de tentar responder o que seria poder, para Foucault, é mais importante averiguar: “[...] quais são, em seus mecanismos, em seus efeitos, em suas relações, os diversos mecanismos de poder que se exercem a níveis diferentes da sociedade, em domínios e com extensões tão variados? [...]" (FOUCAULT, 1979, p. 174).

Nessa acepção, a prática de poder para Foucault:

Ele não é em si mesmo uma violência que, às vezes, se esconderia, ou consentimento que, implicitamente, se reconduziria. Ele é um conjunto de ações sobre ações possíveis; ele opera sobre o campo de possibilidades onde se inscreve o comportamento dos sujeitos ativos; ele incita, induz, desvia, facilita, ou torna mais difícil, amplia ou limita, torna mais ou menos provável; no limite, ele coage ou impede absolutamente, mas é sempre uma maneira de agir sobre um ou vários sujeitos ativos, e o quanto eles agem ou são suscetíveis de agir. Uma ação sobre ações (FOUCAULT, 1995, p. 243).

Outro ponto importante da obra de Foucault para o desenvolvimento deste estudo é o conceito de ordem do discurso. Esse se refere às normas que selecionam, organizam, regulam e redistribuem os discursos. Representa um conjunto de procedimentos que tem a função de exorcizar poderes e perigos, refrear o acontecimento aleatório, "disfarçar a sua pesada e temível materialidade" (FOUCAULT, 1971, p. 14). Incluem formações discursivas atuantes entre si que determinam o que é passível e o que não é de ser enunciado.

A organização, o controle e a regulação do discurso, quando eficientes, conseguem estabelecer regimes de verdade. A verdade será atada a sistemas de poder, que a produzem e a favorecem, instigando-a e propagando-a. Dessa forma, a sociedade é uma arena onde se protagoniza uma batalha pela verdade e pelo papel econômico-político que ela venha a desempenhar. No estudo em questão, a Política Externa de Boa Vizinhança objetivou imprimir como verdade, no Brasil, o modelo sociopolítico e 
econômico estadunidense frente ao nazifascista.

Cada sociedade tem seu regime de verdade, sua "política geral" de verdade, isto é: os tipos de discurso que ela acolhe e faz funcionar como verdadeiros; os mecanismos e instâncias que permitem distinguir os enunciados verdadeiros dos falsos, a maneira como se sanciona uns e outros; as técnicas e os procedimentos que são valorizados para a obtenção da verdade; o estatuto daqueles que têm o encargo de dizer o que funciona como verdadeiro (FOUCAULT, 1979, p. 12).

Conclui-se que os estudos de Foucault, aqui elencados, permitem que o arqueólogo social descreva o discurso da Política Externa de Boa Vizinhança como produto, procurando mostrar como este é percebido como um discurso verdadeiro e com significado em um determinado território e sociedade que constitui suas condições de possibilidade.

\section{Política Externa de Boa Vizinhança}

Segundo a teoria construtivista das Relações Internacionais $^{2}$, a política externa de um país se caracteriza como um veículo de propagação da identidade nacional, sendo que a formação de similitudes e da política externa não é baseada apenas na relação com outros Estados, mas é, também, influenciada pelo discurso apresentado e defendido pela sua diplomacia ao longo de sua história e de grupos que tenham uma visão distinta da identidade e da preservação dos interesses nacionais (GONÇALVES, 2005, p. 36-40).

A política externa de uma nação, desse modo, é resultado da heterogeneidade discursiva da sociedade, gerando a identidade coletiva do Estado, que opera em uma estrutura sistêmica e doméstica, sofrendo mudanças, revelando processos e provocando novas leituras dos seus objetivos. Em suma, a política externa seria a linguagem do sistema internacional, no sentido de ser a prática social e política entre Estados (GONÇALVES, 2005, p. 41).

Sendo a política externa a linguagem do sistema internacional e sabendo que no escopo dos estudos da linguagem, e mesmo dos estudos sociais, está a preocupação em entender o que entra em ação, quando se expressa, o artigo, desse modo, analisará vários aspectos do discurso presentes na Política Externa de Boa Vizinhança.

Executada durante os governos do democrata Franklin Delano Roosevelt - 1933 a 1945, a Política Externa de Boa Vizinhança tornou-se a estratégia de relacionamento com a América Latina naquele período. A principal característica contemplada em seu discurso foi o abandono da prática intervencionista, que prevalecera nas relações dos EUA com a América Latina, desde o final do século XIX, e a adoção de princípios cooperativistas e de ajuda mútua.

A Política Externa de Boa Vizinhança possuía, inicialmente, dois objetivos: recuperar a economia estadunidense, após a Crise de 1929, e conter a crescente presença da Alemanha nazista no comércio com os países da região, especialmente com o Brasil e a Argentina. ${ }^{3}$ Outra intenção importante dessa política era combater o forte antiamericanismo na região.

A Política Externa de Boa Vizinhança buscou, dessa maneira, adotar um discurso enfocando a negociação diplomática e a colaboração econômica e militar com a meta de impedir a influência nazifascista na região, de manter a estabilidade política no continente e de assegurar a liderança estadunidense no hemisfério ocidental. O discurso

\footnotetext{
${ }^{2}$ O construtivismo surgiu pela primeira vez nos estudos das Relações Internacionais na década de 1980, propondo um novo enfoque na abordagem dos fenômenos sociais - fundamentalmente em suas bases culturais e caracteres contingentes - para a compreensão da realidade internacional. Seus principais autores são: Nicholas Onuf, Emanuel Adler e Alexander Wendt. Ver: Sarfati (2006, p. 259).

${ }^{3} \mathrm{O}$ aumento da influência alemã na América Latina ocorreu em razão do comércio compensado, que era o sistema de importação e exportações feitas à base de troca de mercadorias, cujos valores eram contabilizados nas "caixas de compensação" de cada país (CERVO; BUENO, 2002, p. 254).
} 
de cooperação comercial, de solidariedade continental, contra uma possível invasão europeia, e do Pan-americanismo deveria ser reforçado.

No campo da política mundial eu dedicarei esta nação à Política da Boa Vizinhança - uma vizinhança que resulte do respeito mútuo e, devido a isso, respeite o direito dos outros - uma vizinhança que respeite suas obrigações e respeite a santidade dos seus acordos para com todos os seus vizinhos do mundo inteiro (Discurso de posse do Presidente Roosevelt, 4 de março de 1933). ${ }^{4}$

[...] o mais nobre monumento à paz e à boa vizinhança econômica e à amizade social não é feito de bronze ou pedra - é a fronteira que une os Estados Unidos e o Canadá: mais de três mil milhas de amizade, sem arame farpado, canhão ou soldado, e sem passaporte ao longo de toda ela. É a confiança mútua que constrói esta fronteira. Estender esta mesma sorte de confiança por toda a América é o nosso objetivo (Discurso do Presidente Roosevelt realizado em Chautauqua, Nova York, em 14 de agosto de 1936). ${ }^{5}$

Nesse período, houve quatro importantes Conferências hemisféricas: Buenos Aires (1936), Panamá (1939), Havana (1940) e Rio de Janeiro (1942). Analisando os enunciados e as questões debatidas nessas conferências, torna-se evidente o processo gradual que os EUA atravessaram para adotar uma nova linguagem na sua política externa. Essa deveria passar uma imagem - para os demais países americanos - de menos belicosa que as anteriores, além de que a nova política externa deveria ser garantida pela consolidação de laços econômicos duradouros.

\footnotetext{
Nenhuma nação fez sua a vontade de outro povo, mas todas as nações da América hoje só têm uma vontade [...]. A união da vontade das nações não se alcança pela subordinação e sim através de um processo de persuasão e de evolução política, religiosa e espiritual [...]. Iniciamos a construção de uma estrutura econômica americana que atravessará os tempos [...]. Pela primeira vez todo um continente se declara unido para uma ação comum em defesa de um ideal comum, que é o de toda a América. (Chanceler brasileiro, Osvaldo Euclides de Sousa Aranha em discurso realizado no encerramento da $3^{\mathrm{a}}$ Conferência dos Chanceleres no Rio de Janeiro) (ENCICLOPÉDIA..., 1985, p. 96).
}

Depreende-se, assim, que o compartilhamento dos ideais de integração dos países americanos e a construção da identidade de uma só América, pronta para resistir ao imperialismo europeu, voltaram a ter destaque na diplomacia estadunidense. A visão de mundo dos EUA e os valores tradicionais de sua política exterior influenciaram fortemente as diretrizes internacionais adotadas pelos países latino-americanos durante o período estudado.

\section{O Uso dos Meios de Comunicação}

Para combater a rejeição ao American way of life, como modelo para o desenvolvimento da América Latina, e para diminuir a influência nazista na região, os EUA utilizaram, de forma significativa e com eficiência, os meios de comunicações e a política cultural.

O próprio presidente Roosevelt fazia questão de apresentar os bons vizinhos americanos nas suas conversas no rádio ao público estadunidense. Ele utilizava seu forte apelo político, enquanto os meios de comunicação ficavam encarregados de criar e apresentar o perfil de um tipo latino-americano. A América Latina era visualizada por meio de um conjunto de representações marcadas pelo avanço das técnicas de imagens e sons: o cinema, o rádio e a fotografia. Essa sofisticação técnica, ademais, produzia uma verdadeira saturação identitária pela veiculação contínua de imagens que ostentavam o objetivo de venderem o American Way of Life e o Pan-americanismo. A profusão dessas imagens agia como um dispositivo de etiquetagem e de disciplinamento do corpo social (MAUAD, 2005, p. 56).

Em 16 de agosto de 1940, o governo estadunidense criou o Office of the coordinator of Inter-American Affairs - OCIAA. O órgão era encarregado, entre

\footnotetext{
${ }^{4}$ Discurso disponível em: Presidential Speech Archive. Miller Center - University of Virginia. Franklin Roosevelt - First Inaugural Address (March 4, 1933). Disponível em: <http://millercenter.org/president/speeches/detail/3280>. Acesso em: 25 jan. 2013.

${ }^{5}$ Informação disponível em FDR Presidential Library - vídeo no 266 . Disponível em: <http://archive.org/details/gov.fdr.266>. Acesso em: 25 jan. 2013.
} 
outras coisas, de regular, desenvolver, redistribuir, organizar e selecionar projetos de aproximação cultural coincidentes com o discurso enunciado pela Política Externa de Boa Vizinhança para a América Latina. Vinculado ao Conselho de Defesa Nacional dos EUA, o OCIAA tinha como diretor o empresário milionário estadunidense Nelson Aldrich Rockefeller, proprietário, entre outros bens, da Standard Oil (TOTA, 2000, p. 50).

O jornalista do The New York Times, James Reston, em um artigo publicado no jornal que ele representava, afirmou que os objetivos do OCIAA eram:

[...] persuadir a América Latina a cerrar fileiras com nossas forças em ações defensivas contra a ameaça alemã [...] convencê-las de que temos a resposta para as questões econômicas e militares [...] e acima de tudo convencer todos os latino-americanos de que a Política de Boa Vizinhança não é um expediente temporário para nos ajudar nessa dura tarefa, mas uma atitude sincera e permanente, exatamente o contrário de nossa "diplomacia do dólar" e do Destino Manifesto, no século XIX (RESTON apud TOTA, 2000, p. 186).

O OCIAA foi criado para gerar unicidade e ordem na produção discursiva da Política Externa de Boa Vizinhança. Os formuladores da Política Externa de Boa Vizinhança objetivavam concentrar, no órgão, o papel de mediação entre o público e a realidade. O que o OCIAA oferecia não era a realidade, mas uma construção que permitiria ao receptor produzir formas simbólicas de representação da sua relação com a realidade concreta.

Os EUA deveriam ser apresentados, segundo a visão de Nelson e de sua equipe, como um país possuidor do "segredo do progresso" e que estariam dispostos a compartilhar com seus vizinhos americanos. As transmissões de rádio, o cinema, os projetos de saneamento e de saúde e os programas econômicos estavam imbuídos desse sentido paradigmático de que os EUA eram o modelo a ser seguido na região (TOTA, 2000, p. 180).
Por meio de programas radiofônicos, revistas, (Time, Life e Seleções Reader's Digest), cinema e anúncios publicitários, o OCIAA atuava em resposta à propaganda nazifascista na América Latina. ${ }^{6}$ Esses divulgavam informações positivas dos EUA e de sua política externa. Eles promoviam o panamericanismo, o comércio e passavam uma imagem favorável das outras "Repúblicas" americanas (TOTA, 2000, p. 55).

O diretor do OCIAA, Rockefeller, acreditava que o futuro dos investimentos nos países da região dependia da venda de dois itens: de produtos e do modo de vida estadunidense. O sucesso no setor econômico estava condicionado, portanto, ao êxito no campo ideológico (TOTA, 2000, p. 54). Um marco dessa forma de pensar de Rockefeller foi o lançamento da Coca-Cola no Brasil em 1942.

Sendo uma marca importante dentro dos EUA, a Coca-Cola buscou ressaltar em suas campanhas publicitárias o Pan-americanismo e o American Way of Life, po ${ }^{1} \mathrm{Na}$ Itália, quem coordenava as ações propagandistas e culturais era Ministério da Cultura Popular, habitualmente chamado pelo termo "Minculpop", juntamente com o Instituto Luce. A comunicação e a propaganda do regime Nazista ficavam por conta de Joseph Goebbels e de seu Ministério Nacional para Esclarecimento do Povo e Propaganda e a Universum - Film AG. - UFA, indústria cinematográfica alemã que rivalizava diretamente com Hollywood.

Porém, sem deixar de focar na conquista do mercado da região. Em seu anúncio publicitário, o grande círculo vermelho, símbolo comercial da empresa, trazia o mapa do continente americano e o slogan "unidas hoje, unidas sempre". Desta forma, vendia o produto e passava a mensagem da aliança pan-americana.

A empresa de refrigerante, ao se estabelecer no

\footnotetext{
${ }^{6} \mathrm{Na}$ Itália, quem coordenava as ações propagandistas e culturais era Ministério da Cultura Popular, habitualmente chamado pelo termo "Minculpop", juntamente com o Instituto Luce. A comunicação e a propaganda do regime Nazista ficavam por conta de Joseph Goebbels e de seu Ministério Nacional para Esclarecimento do Povo e Propaganda e a Universum - Film AG. - UFA, indústria cinematográfica alemã que rivalizava diretamente com Hollywood.
} 
Brasil, presenteou um ministro de Estado com uma caixa de seu produto que acompanhava uma carta relacionando a Coca-Cola à colaboração hemisférica entre o Brasil e os EUA. Segue trecho da carta: "Em comemoração ao lançamento do famoso produto Pan Americano Coca Cola, Coca-Cola Refrescos S.A tem a súbita honra de oferecer a V. Excia, uma caixa do seu refrigerante. [...] esperamos que o mesmo constitua um elo de fraternidade entre as Américas." (MOURA, 1988, p. 72).

Não foi somente a Coca-Cola que buscava associar sua marca ao Pan-americanismo, era comum encontrar nos anúncios publicitários, veiculados nas principais revistas brasileiras, empresas adotando a mesma estratégia.

A Kodak, em determinado anúncio, durante a guerra, agradecia a paciência e a cooperação dos clientes brasileiros, na falta de seu produto, e afirmava que esta postura foi essencial para que pudessem enfrentar, com êxito, "o que podia ter sido uma situação perigosa para todos”. O anúncio ainda afirmava que os filmes da Kodak eram vitais para os que lutavam pela liberdade e que, no pósguerra, estariam disponíveis a todos.

Havia, ademais, o cartaz da Parker, que fabricava canetas. Essas eram apresentadas ao lado de munições bélicas, e o slogan afirmava que a caneta "nunca foi tão preciosa como hoje". A empresa Philco divulgava, em seus anúncios, dois globos terrestres: um representando os dias de hoje e a guerra, com o mapa da Europa sendo cortado por uma espada, e outro representando o amanhã, onde, do mapa do continente americano, brotava um ramo que simbolizava o porvir de uma nova vida. $\mathrm{O}$ anúncio salientava que a pesquisa de guerra proporcionaria um amanhã de "novos prazeres para V.S e seu lar... em rádio, fotografia, televisão, refrigeração e ar condicionado". Novidades que simbolizavam a modernidade da sociedade estadunidense perante as demais.
$\mathrm{Na}$ mesma linha, iam os anúncios da Easy Washing, fabricante de máquinas de lavar. A empresa prometia facilitar a vida das donas de casa, não esquecendo de fomentar a cooperação entre as Américas, ao estampar um símbolo, no canto direito dos seus anúncios, onde se lia: "as Américas unidas, unidas vencerão"?.

Observa-se que articuladas a outros enunciados que dialogam nos meios de comunicação, as ações comerciais e de cooperação internacional são verdadeiros dispositivos discursivos dos quais se instalam representações e forjam-se diretrizes que orientam a criação simbólica da identidade.

[...] o projeto de anúncios em jornais e revistas é "parte de um esforço amplo de bom vizinho para promover a ajuda entre as Américas". O projeto se cassava bem com as noções de "esforço de guerra" de todo o continente: os anúncios explicavam as razões da escassez naquele momento e a necessidade de sacrifícios imediatos (no consumo) de modo a garantir a abundância do futuro (pós guerra) (MOURA, 1988, p. 69).

No rádio, o OCIAA apresentava programas transmitidos diretamente dos EUA ou por estações locais. Alguns programas de rádio fizeram bastante sucesso como: Voz da América, O Brasil na Guerra, A Família Borges, Barão Eixo e o noticiário mais famoso da época $\mathrm{O}$ Repórter Esso.

No Brasil, o Repórter Esso teve início em 1941 e tornou-se o principal noticiário radiofônico brasileiro. Ele era transmitido em várias edições diárias e veiculava, além de notícias, propagandas político-ideológicas e culturais com a intenção de influenciar o governo e a sociedade brasileira (KLÖCKNER, 2004, p. 1).

Durante reunião, realizada no Rio de Janeiro, em 23 de janeiro de 1942, onde os países americanos reafirmaram sua solidariedade continental, o Repórter Esso cobriu o acontecimento da seguinte maneira:

Foi a maior derrota diplomática do nazi-fascismo, literalmente batido nas suas investidas de infiltração

\footnotetext{
${ }^{7}$ Os anúncios estão na Revista Seleções dos meses de maio, junho, julho e agosto de 1944. Ver: Biblioteca Nacional, Rio de Janeiro. Seção de Periódicos: Seleções do Reader's Digest.
} 
num continente tão visado pela sua política agressora de espaço vital. A sábia Política de Boa Vizinhança preconizada por Roosevelt, e tão bem compreendida pelos demais estadistas do continente, recolhe os seus frutos mais concretos, e as Américas declaramse unidas, condenando em declaração histórica, os agressores mundiais (REPÓRTER ESSO, 23 JAN. 1943 apud KLÖCKNE, 2001, p. 8).

Em relação à queda do regime fascista italiano, em 1943, o programa radiofônico de maior audiência brasileiro afirmou: "Caiu o tragicômico Duce do sanguinário fascismo. Quinze dias após a invasão da Sicília, o poderoso regime de Mussolini não resistia ao Primeiro knock - out que os anglo - americanos lhe aplicaram em sua própria casa [...].” (REPÓRTER ESSO, 25 JUL.1943 apud KLÖCKNE, 2001, p. 9). ${ }^{8}$

A respeito da difusão da Política Externa de Boa Vizinhança e de informações sobre o Brasil, há algumas passagens do programa News of the World ou Evening News que merecem destaque.

O Brasil aparecia com mais destaque no noticiário. O próprio presidente Roosevelt mandava uma bemhumorada mensagem ao seu "largest neighbor that is standing shoulder to shoulder with the United States". A importância do Brasil e de seus produtos para os Estados Unidos era sempre enfatizada. [...] $\mathrm{Na}$ sequência entrava um comercial: "Sempre que você tomar um café brasileiro, você estará comprando a Política da Boa Vizinhança. Compre café brasileiro... se você for a favor da Política da Boa Vizinhança." (TOTA, 2000, p. 109).

Percebe-se, nos textos analisados de O Repórter Esso, a presença de diferenciados adjetivos, enaltecendo os feitos dos Aliados, como: vigorosa luta; poderosas forças; histórica resistência; gigantesco orçamento; tenaz batalha; sábia Política da Boa Vizinhança de Roosevelt; ou atribuindo aspectos depreciativos ao Eixo como: sanguinário fascismo; agressores; tragicômico Duce; inimigos; graves atitudes; derrotados (KLÖCKNER, 2004, p. 13).

A indústria cinematográfica foi outro meio de comunicação utilizado na divulgação da política externa do governo de Roosevelt. Em 1940, foi fundada a seção de cinema da Divisão de Comunicação do OCIAA, a Motion Picture Divison (MPD). Essa tinha as seguintes funções: promover a produção interna de filmes (curtas e longas), de cinejornais sobre os EUA e as "outras Américas" e distribuí-los para os países da região. Além de combater, por todas as formas, o cinema produzido pelo Eixo, por meio da indústria cinematográfica alemã, Universum-Film AG (Ufa) (TOTA, 2000, p. 65).

A MPD orientou os estúdios a não caracterizar os latino-americanos como vilões ou bandidos, esses deveriam ser os nazifascistas. Desse modo, aos poucos, os famosos foras da lei mexicanos, tão comuns nos filmes de faroeste, cederam lugar aos vilões nazistas. A sensualidade da mulher e a coragem e simpatia do homem latino-americano foram enaltecidos.

O OCIAA, ciente de que o cinema era um poderoso instrumento de diplomacia, tratou de convocar renomados artistas para serem verdadeiros embaixadores e divulgadores da Política Externa de Boa Vizinhança. Como exemplo, destacam-se: Walt Disney, Tyrone Power, Douglas Fairbanks Jr., Lana Turner, John Ford, Genevieve Naylor, George Orson Welles e Carmen Miranda.

A partir desse momento, os EUA começaram a ser rotulados, por Hollywood, nas películas, como uma nação que estava enfrentando uma árdua luta do "bem contra o mal", em que seus heroicos e simpáticos soldados travavam uma longa batalha contra os autoritários, desumanos e malvados nazistas, no fronte ocidental, e contra os sanguinários, fanáticos e suicidas japoneses, no fronte oriental. Dessa forma, os filmes hollywoodianos apresentavam o discurso de que os estadunidenses eram os líderes da democracia e os legítimos representantes do "mundo das luzes" em luta contra a escravização imposta pelos regimes totalitários.

Um dos principais agentes dessas políticas e criador de personagens emblemáticos, como Joe

\footnotetext{
${ }^{8}$ As radiodifusões estão disponíveis para consulta na Fundação do Museu da Imagem e do Som - MIS, Rio de Janeiro. Ver: Coleção Rádio Nacional
} 
Carioca (Zé Carioca) e Panchito, foi Walt Disney. O renomado desenhista e diretor esteve no Brasil em junho de 1941, afirmando que estava à procura de novos talentos, buscando inspiração para suas obras e para divulgar seu novo trabalho "Fantasia". No entanto, Disney estava, também, a serviço do OCIAA e na sua agenda havia encontros com autoridades governamentais, como o próprio presidente Getúlio Dorneles Vargas, bem como declarações à imprensa, promovendo a integração continental sob a Política da Boa Vizinhança.

Como fruto de suas pesquisas na América do Sul, em 1942, os estúdios Walt Disney apresentaram o desenho animado "Alô amigos!". No filme, alguns países da região como: Bolívia, Chile, Colômbia, Peru e Venezuela, e com mais destaque Brasil e Argentina, são apresentados ao telespectador. No Brasil, o ranzinza Pato Donald é recebido pelo simpático e malandro Joe Carioca, enquanto que, na Argentina, o atrapalhado Pateta se interage com os corajosos e valentes gaúchos.

O segundo filme da Disney, encomendado pelo OCIAA, foi lançado apenas em 1945, o desenho animado "The Three Caballeros", que no Brasil recebeu o nome de "Você já foi à Bahia?". Nessa produção, a Argentina não é retratada por Walt Disney, pois a conjuntura internacional e as alianças em relação à Segunda Guerra Mundial já se encontravam bem definidas, e a Argentina se declarava neutra. O filme apresenta, ludicamente, os três principais aliados americanos atuando em conjunto, são eles: Joe Carioca (Brasil), Pato Donald (EUA) e Panchito (México).

Outro diretor e produtor reconhecido que esteve no Brasil, chegando até mesmo a comandar seu próprio programa de rádio no país, foi o cineasta George Orson Welles. O diretor do premiado "Cidadão Kane" esteve no Brasil, em fevereiro de 1942, para filmar "It's All True”. O filme apresentaria o carnaval carioca, a semana santa em Minas Gerais e a história de quatro jangadeiros cearenses que realizaram uma travessia por mar de 1.000 milhas até Rio de Janeiro. ${ }^{9}$

A visita de Welles e seu desempenho como embaixador cultural estadunidense, na América do Sul, financiado pelo OCIAA, ficaram documentados no Memorandum CO-948 de 27 de abril de 1942 do órgão. Nesse fica evidente que, além das filmagens para seu novo filme, o célebre diretor era agente cultural do OCIAA. Entre os compromissos de Welles, destacavam encontros com jornalistas, reuniões com empresários, banqueiros, escritores, artistas, acadêmicos, intelectuais, personalidades dos meios de comunicação, além de políticos ligados ao governo, tornando-se íntimo da família Vargas, do chancelar brasileiro Osvaldo Aranha e do interventor de Minas Gerais, Benedito Valladares Ribeiro. Em todos esses eventos, o diretor procurava promover a importância da integração continental e os princípios da Política Externa de Boa Vizinhança (ZAGNI, 2008, p. 85).

O filme de Welles, no entanto, nunca chegou a ser lançado. O diretor entrou em atrito com Nelson Rockefeller, sócio majoritário da produtora de seu filme a Radio-Keith-Orpheum (RKO) Pictures. Tudo indica que tanto a produtora quanto o Departamento de Imprensa e Propaganda (DIP) estavam incomodados com o enfoque dado por Welles ao caso dos jangadeiros cearenses e suas lutas por melhores condições de trabalho e por direitos previdenciários - aliás, o DIP acusava o líder dos jangadeiros, Manuel Olímpio (o Jacaré), de ser comunista.

A $R K O$ e o DIP não estavam satisfeitos, também, com as filmagens realizadas no Rio de Janeiro, onde se destacavam o cenário das favelas e as manifestações culturais de seus moradores, como o samba e o candomblé. Aos olhos do regime

${ }^{9}$ Em entrevistas, Orson Welles afirmou que teria lido, em 1941, na conceituada revista estadunidense Time uma reportagem sobre a travessia de quatro jangadeiros de Fortaleza, Manuel Olímpio (o Jacaré), Jerônimo de Sousa, Raimundo Lima e Pereira da Silva, para o Rio de Janeiro. Os jangadeiros, segundo a reportagem, teriam percorrido esse longo percurso para solicitar, ao presidente Getúlio Vargas, seus direitos previdenciários (SANTOS, 2009, p. 340-343). 
varguista e do OCIAA, acreditava-se que Welles se dedicaria a filmar somente as belezas naturais do Rio de Janeiro, enaltecendo a receptividade do carioca. Assim, não se previam cenas rodadas em favelas e que reconstruíssem, em estúdio, a demolida Praça Onze de Junho. ${ }^{10}$

Além de enviar artistas estadunidenses para o Brasil, os EUA, também, abriram as portas para os talentos brasileiros. A cantora e atriz luso-brasileira, Maria do Carmo Miranda da Cunha, conhecida como Carmen Miranda, alcançou enorme sucesso nos meios de comunicação estadunidenses.

Em 1939, o produtor Levi "Lee" Shubert, que conhecera Carmen Miranda por intermédio do ator hollywoodiano, Tyrone Edmund Power Jr., contratou-a como artista exclusiva da Select Operating Corporation para atuar e cantar no musical "Streets of Paris" na Broadway. A montagem foi sucesso de público e de crítica. O carisma e o desempenho da Pequena Notável levou Shubert a afirmar que Carmem Miranda estaria fadada a fazer mais pela solidificação das boas relações entre os Estados Unidos e a América do Sul do que os próprios diplomatas (MENDONÇA, 1999, p. 73).

No ano de 1940, a MPD produziu o primeiro filme estrelado por Carmen Miranda, "Down Argentine Way”. O filme foi sucesso de bilheteria nos EUA, mas alvo de críticas na Argentina, uma vez que as personagens foram consideradas demasiadamente estereotipadas. No mesmo ano, a cantora e atriz se apresentou ao presidente Roosevelt em um banquete na Casa Branca, em razão de seu sétimo ano de ascensão à presidência.

Durante sua passagem por Hollywood, Carmen Miranda atuou em catorze filmes ${ }^{11}$, ao lado de estrelas como Don Ameche, Groucho Marx, Alice
Faye e Cesar Romero. Chegou a ser a mulher mais bem paga do cinema estadunidense e a maior arrecadadora de impostos pelo seu faturamento como atriz.

Enfim, após enumeração e elucidação de como o governo de Roosevelt utilizou seu soft power ${ }^{12}$, um dos principais instrumentos da Política Externa de Boa Vizinhança, pode-se concluir que a diplomacia cultural de uma nação, conquanto não seja hábil de mudar drasticamente a ação de um país, redirecionando-a, pode agir na base de seus ideais e valores, ao intercambiar e transformar visões de mundo. É possível entender esse processo nas palavras de Nicholas Onuf, para quem a linguagem tem uma função ímpar, e no pensamento de Joseph Nye, um dos maiores estudiosos sobre o poder da cultura das relações internacionais.

While each of us lives in a whole world that is uniquely our own, we share worlds by speaking about them to each other. Worlds that we speak of can only be partial and highly selective representations of what we see. We make these representations more or less compatible by telling each other not just what we (want them to) see but what we want them to do, and why they should do it. Speaking about worlds is always normative. By speaking, we narrow down the number of worlds that we are collectively able to identify. To the extent that some number of observers commonly represent some set of social relations as a world (whether they belong to it or not), then they have made a world for themselves collectively, but not necessarily for the agents whose world (they say) it is (ONUF, 2002, p. 121).

[...] a universalidade da cultura de um país e sua capacidade de estabelecer um conjunto de normas e instituições favoráveis que governem setores de atividade internacional são fontes decisivas de poder. Os valores da democracia, da liberdade pessoal, na mobilidade social e da abertura, frequentemente expressos na cultura popular americana, a instrução superior e a política externa contribuem com o poder do nosso país em muitas áreas (NYE JUNIOR, 2002, p. 37).

\footnotetext{
${ }^{10}$ Entrevista de Orson Welles, publicada no Cahiers du Cinéma, concedida aos jornalistas franceses André Bazin e Charles Bitsch (1958).

${ }^{11}$ Down Argentine Way; That night in Rio; Week-end in Havana; Springtime in the Rockies; The Gang's all here; Four jills in a jeep; Greenwich Village; Something for the boys; Doll face; If I'm lucky - todos estes pela 20th Century Fox e ainda por outras produtoras: Copacabana; A date with Judy; Nancy goes to Rio; Sacared Stiff.

${ }_{12}$ Joseph Samuel Nye Jr. desenvolveu o termo soft power para descrever o poder cultural-ideológico de um país. Desse modo, para o autor, o soft power é a capacidade de um país atingir seus objetivos pela influência de seus valores, cultura e política. Enquanto o hard power é representado pelo poder militar e econômico de um Estado (NYE JUNIOR, 2004, p. 5).
} 


\section{Considerações Finais}

Infere-se que a realidade social é constituída, sobretudo, pelas estruturas de conhecimento, baseadas nos entendimentos compartilhados - os intersubjetivos determinam o real e o irreal, o concebível e o inconcebível, o positivo e o negativo, fazendo com que o controle sobre a produção e a reprodução desses significados, presentes no discurso da política externa de um Estado, forneçam instrumentos de controle sobre a própria realidade.

Nessa perspectiva, a Política Externa de Boa Vizinhança desempenhava os objetivos de controlar, pacificamente, e smart ${ }^{13}$, o crescente antiamericanismo e a simpatia dos governantes pelos regimes nazifascistas na região, inclusive no Brasil, bem como visava intensificar o fluxo comercial entre as nações latino-americanas com os EUA. Não era interesse de Roosevelt, além disso, e de seus assessores mais próximos que o país se envolvesse em uma intervenção armada na região, pois outro cenário mais duro estava se estabelecendo na Europa.

Em suma, o que se procurou demonstrar, neste artigo, foi que os aspectos culturais produzidos pela Política Externa de Boa Vizinhança e vendidos aos demais países latino-americanos divulgaram estilos de vida, conceitos, visões, consubstanciando-se em uma das primeiras exportações de versões idealizadas do American way of Life. Isso ocorreu, pois os formuladores da política externa de Roosevelt perceberam que o discurso tem a capacidade de estabelecer a verdade e de criar a realidade, podendo ser amplamente produzido ou divulgado pelos meios de comunicação.

O empenho em fabricar discursos de identidades, desenvolvido pelos setores midiáticos e culturais na Política Externa de Boa Vizinhança, desempenhou, ademais, atribuições sociais básicas habitualmente executadas pelos mitos, como a reprodução de simbologias culturais, a massificação e a integração social dos indivíduos. $\mathrm{O}$ emprego das imagens projetadas, seja diretamente, como no cinema e nas revistas, ou indiretamente, caso do rádio, foi afiançado pela ampla oferta de padrões disseminados e estabelecidos socialmente pela técnica de imitação e formas ritualizadas. Esses moldes identitários são socialmente convenientes, pois instituem paradigmas, procedimentos, estereótipos e opiniões que representativamente acabam por inserir o indivíduo na "comunidade idealizada".

Por fim, é importante ressaltar que os produtos culturais, materiais e ideológicos produzidos pelos EUA não podem ser deslocados de certas condições de receptividade na sociedade brasileira como: esperança de bem-estar, procura por liberdades e igualdades, desigualdades sociais, fraquezas politicas e econômicas, ideais compartilhados, entre outros. Portanto, por mais eficazes que as técnicas de ações psicológicas empregadas pelos meios de comunicação pareçam, é incorreto imaginar que elas estão à disposição de qualquer aparelho, visando a qualquer fim. É preciso que haja um conteúdo político, uma identidade e uma ressonância na população.

\section{Referências}

BAZIN, A.; BITSCH, C.. Entretien avec Orson Welles. Cahiers du Cinéma. Paris, t. 14, n. 84, p. $1,1958$.

BROWN, W. Power after Foucault. In: DRYZEK, John S.; HONIG, Bonnie; PHILLIPS, Anne (Ed.). The oxford handbook of political theory. London: Oxford University Press, 2008.

CERVO, A. L.; BUENO, C. História da política exterior do Brasil. Brasília: Instituto Brasileiro de Relações Internacionais/EdUnB, 2002.

CROCKER, C. A; HAMPSON, F. O. Leashing the dogs of war: conflict management in a divided world. USA: Institute of Peace Press, 2007.

\footnotetext{
${ }^{13} \mathrm{O}$ Estado quando consegue combinar os dois poderes, o hard power e soft power de forma sensata e eficaz, gera o smart power. Ver: Nye Junior (2004, p. 32) e Crocker e Hampson (2007, p. 13).
} 
DELEUZE, G. Foucault. São Paulo: Brasiliense, 2006.

ENCICLOPÉDIA nosso século. São Paulo: Abril Cultural, 1985. v. 6, p. 96. (1930-1945 - A Era de Vargas, $2^{\mathrm{a}}$ parte).

FOUCAULT, M. Microfisica do poder. Rio de Janeiro: Edições Graal, 1979.

. O sujeito e o poder. In: RABINOW, P.; DREYFUSS, H. Michel Foucault: uma trajetória filosófica. Rio de Janeiro: Forense Universitária, 1995.

1971.

A ordem do discurso. Paris: Gallimard,

GONÇALVES, M. V. A voz da identidade nacional: a política externa russa como prática dialógica excludente dos chechenos. 2005. Dissertação (Mestrado em Relações Internacionais) - Pontifícia Universidade Católica, Rio de Janeiro. 2005.

GREGOLIN, M. R. V. Análise do discurso e mídia: a (re) produção de identidades. Revista Comunicação, Mídia e Consumo, São Paulo, v. 4, n. 11, p. 11-25, 2007.

KLÖCKNER, L. O repórter Esso e Getúlio Vargas. In: CONGRESSO BRASILEIRO DE CIÊNCIAS DA COMUNICAÇÃO, 27., 2004, Porto Alegre. Anais... São Paulo: INTERCOM, 2004. CD-ROM.

- O Repórter Esso e a Globalização: a produção de sentido no primeiro noticiário radiofônico mundial. In: CONGRESSO BRASILEIRO DA COMUNICAÇÃO, 23., 2001, Campo Grande. Anais... Campo Grande: INTERCOM, 2001. Disponível em: <http://www. intercom.org.br/papers/nacionais/2001/papers/ NP6KLOCKNER.PDF>. Acesso em: 20 mar. 2012.

MACHADO, R. Ciência e saber: a trajetória da arqueologia de Michel Foucault. Rio de Janeiro: Edições Graal, 1981.

MAUAD, A. M. Genevieve Naylor, fotógrafa: impressões de viagem (Brasil, 1941-1942). Revista Brasileira de História, São Paulo, v. 25, n. 49, p. 43-75, jun. 2005.

MENDONÇA, A. R. Carmen Miranda foi a Washington. Rio de Janeiro: Record, 1999.

MOURA, G. Tio Sam chega ao Brasil: a penetração cultural americana. São Paulo: Brasiliense, 1988.

NYE JUNIOR, J. S. Soft power: the means to success in world politics. USA: Public Affairs, 2004.

. O paradoxo do poder americano: por que a única superpotência do mundo não pode prosseguir isolada. São Paulo: EdUnesp, 2002.

ONUF, N. Worlds of our making: the strange career of constructivism in international relations. In: PUCHALA, D. Visions of international relations: assessing an academic field. Columbia: University Of South Carolina Press, 2002.

ROUSE, J. "Power/Knowledge" In: GUTTING, Gary (Ed.). The cambridge companion to foucault. Cambridge: Cambridge University Press, 1994.

SANTOS, Márcia Juliana. Em cena: quatro homens numa jangada. A luta por direitos dos jangadeiros dos cearenses em 1941. Projeto História, São Paulo, n.39, p. 339-349, jul./dez. 2009

SARFATI, G. Teorias de relações internacionais. São Paulo: Saraiva, 2005.

TOTA, A. P. $O$ imperialismo sedutor: a americanização do Brasil na época da Segunda Guerra. São Paulo: Cia. das Letras, 2000.

ZAGNI, R. M. "Imagens projetadas do império" o cinema hollywoodiano e a construção de uma identidade americana para a política da boa vizinhança. Cadernos PROLAM/USP, São Paulo, ano 8, v. 1, p. 67-91, 2008. 
